by a quantitative approach is worth serious examination and it is a pity that this brave beginning is open to a wide range of objections, of which one is the small size of the sample used. Thus in the period 1778-80 one new author could write $20 \%$ of the articles cited. The problem of the disproportionate number of articles written by Lavoisier himself is fully appreciated by the author, who presents data in alternative forms to meet this objection. There is also the problem of biographical detail for some of the lesser well known chemists which might affect the picture of the 'average chemist'. Finally it is not clear to the reviewer how we can count "oxygen articles" in journals before the discovery of oxygen.

I am sure that a careful use of a quantitative approach may provide valuable new insights in understanding the development of science but it will be all the more useful if it is brought in as an additional tool rather than as an alternative. In counting heads let us not ignore what was in those heads.

Maurice Crosland is Director of the Unit for the History, Philosophy and Social Studies of Science at the University of Kent at Canterbury, UK.

\section{Respecting aberrant figures}

\section{J. R. Ravetz}

Man and Nature in the Renaissance. By A. G. Debus. Pp. 159. (Cambridge University Press: Cambridge and London, 1978.) Hardback £7.95; paperback $£ 2.50$.

THE history of the science of the period of the Renaissance is directly relevant to the practice of science today, for our present ideas of what constitutes genuine science, and what demarcates it from false imitations, were forged then. For a very long time it had been common for historians to take the evaluations of the seventeenth-century innovators as simple fact: those who adhered to older methodologies of world-views were simply reactionaries, fools or charlatans. Scientists who achieved great science (by our standards) in spite of such defects (as Kepler or Gilbert) were explained as being "strange mixtures of the old and the new".

In recent decades, there has been a thin but growing stream of research that treats some of the aberrant figures with respect, both for their staature in their own times and for such 'positive" achievements as can be gleaned from their work. The most promising candidates for such re-evaluation are in the tradition of alchemically tinged practical chemistry, relating directly to metallurgy, medicine, and having implications for philosophy, religion and politics. The leading figures in that 'chemical philsophy' were Paracelsus and van Helmont; its leading interpreters Page, Rattansi and Debus.

Now this school has produced an introductory textbook by which students are shown how much more there was to the scientific revolution than the developments centring on the work of Galileo. In it we find brief and illuminating accounts of the "chemical philosophy'. Otherwise, it is a competent survey of developments in science and in methods in the sixteenth and early seventeenth centuries. As it is read and used, we may expect that the 'chemical philosophy' will achieve a sort of respectability among those who learn or teach the history of science.

This is a very valuable achievement. A most urgent educational task is to show that the Galilean style of reductionist, abstracted research is not the uniquely true approach to a proper knowledge and control of nature. A modest and uncontroversial introduction to a broader conception of science

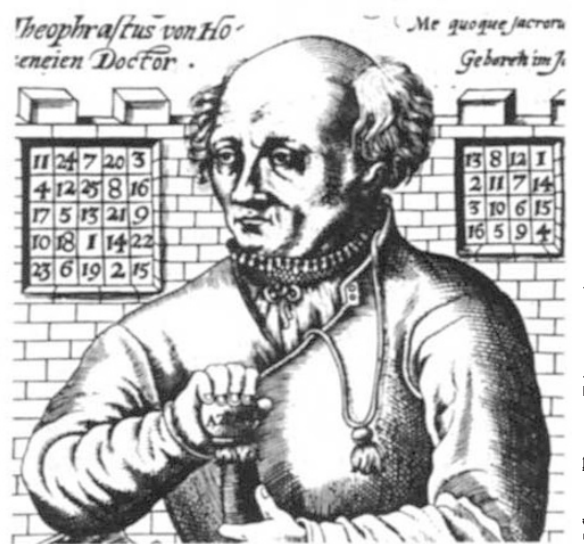

\section{SCIENTIFIC BOOKSHOP}

H. K. LEWIS can supply works in all branches of Pure and Applied Science. Catalogues. on request. Please state interests.

\section{SCIENTIFIC \\ LENDING LIBRARY}

Annual Subscription from $\mathbf{£ 7 . 5 0}$. (Available in U.K. only)

Reduced rates for multiple subscriptions.

Prospectus post free on request.

Quarterly List of New Books and new editions added to the Library sent post free to subscribers regularly.

\section{H. K. LEWIS \& Co. Ltd. 136 GOWER STREET, LONDON, WC1E 6BS}

Telephone: 01-387 4282

Telagrams: "Publlcavit,

Tolograms: "Publicayt,

Circle No. 63 on Reader Enquiry Card

will have a greater diffusion in teaching establishments than a strident polemical tract. But a price is paid for this very Fabian approach to intellectual reform; there is a loss, not so much of ideological militancy as of historical drama. Our sort of science was conceived and propagated by men with a prophetic mission. The issues in their debates ranged over all human values and experience. Different conceptions of reality were in open collision then, and ideological commitments (based on a fusion of political and theological concerns) could be as important as experimental facts in determining positions in the still immature natural sciences of the time. Of all this, we get only the most mild of hints. The received historical doctrine of the rise of modern science as an automatic consequence of the adoption of correct attitudes and methods, is here not so much challenged as modified at the fringe. But perhaps that is appropriate for a pioneering venture in textbook writing; and as a simple, lucid and accessible introduction to its subject, the book succeeds well.

J. R. Ravetz is Reader in the History and Philosophy of Science at the University of $\Sigma$ Leeds, UK. 